\title{
Water-Quality Variables across Sekisei Reef, A Large Reef Complex in Southwestern Japan ${ }^{1}$
}

\author{
Naoko Morimoto, ${ }^{2,6}$ Yasuo Furushima, ${ }^{3}$ Masayuki Nagao, ${ }^{4}$ Takabiro Irie, ${ }^{2}$ Akira Iguchi, ${ }^{5}$ \\ Atsushi Suzuki, ${ }^{4}$ and Kazubiko Sakai ${ }^{2}$
}

\begin{abstract}
At Sekisei Reef in southwestern Japan $\left(24^{\circ} \mathrm{N}\right)$, coral cover dramatically decreased in the mid-1980s, probably due to a population outbreak of the coral predator Acanthaster planci. Coral communities subsequently recovered well outside the semiclosed lagoon, but recovery has been poor inside it. Hence, water-quality degradation including eutrophication has been a concern inside the lagoon. In addition, temporal variation in eutrophication parameters is common among high-latitude coral reefs, resulting in difficulties in evaluating them. Therefore, to address these issues, we monitored temperature, salinity, turbidity, chlorophyll- $a, \mathrm{NO}_{x}-\mathrm{N}\left(\mathrm{NO}_{3}-\mathrm{N}+\mathrm{NO}_{2}-\mathrm{N}\right)$, and $\mathrm{NH}_{4}-\mathrm{N}$ concentrations year-round across the lagoon at Sekisei Reef. Turbidity and $\mathrm{NO}_{x}-\mathrm{N}$ concentration increased with increasing wind velocity, suggesting that variation in turbidity and $\mathrm{NO}_{x}-\mathrm{N}$ concentrations was attributed to resuspension of bottom sediments, and $\mathrm{NO}_{x}-\mathrm{N}$ release through regeneration processes of microorganisms from the sediments and reef frameworks, respectively. In contrast, variation in chlorophyll- $a$ and $\mathrm{NH}_{4}-\mathrm{N}$ concentrations appears to be mainly controlled by the seasonality of temperature and irradiance. Long retention time of seawater inside the lagoon seems to have enhanced $\mathrm{NH}_{4}-\mathrm{N}$ assimilation and increase of phytoplankton during summer. Inside the lagoon, turbidity, $\mathrm{NO}_{x}-\mathrm{N}$, and summer chlorophyll- $a$ concentrations were higher, and variation in temperature was larger than outside it. Although water quality appears not to be seriously degraded, multiple effects of these water-quality variables might have negatively affected recovery of coral communities inside the lagoon. Recent expansion of land use on nearby islands might have contributed to water-quality degradation inside the lagoon.
\end{abstract}

MANY CORAL REEFs are threatened by degradation both globally and locally (e.g., Wilkinson 2004, Knowlton and Jackson 2008). At

\footnotetext{
${ }^{1}$ This study was partly supported by a Kurita Water and Environment Foundation Research Grant Program, "Study on the Selection of Biodiversity Conservation Areas of Coral Reefs" fund provided by the Ministry of the Environment of Japan, a grant from the 21st Century COE program, "The Comprehensive Analyses on Biodiversity in Coral Reef and Island Ecosystems in Asian and Pacific Regions," from the Ministry of Education, Culture, Sports, Science, and Technology of Japan, and the Japan Society for the Promotion of Science, Grantsin-Aid Nos. 16310158, 18651112 and 21570021. Manuscript accepted 16 December 2008.
}

Pacific Science (2010), vol. 64, no. 1:113-123

doi: $10.2984 / 64.1 .113$

(C) 2010 by University of Hawai'i Press

All rights reserved
Sekisei Reef in East Asia (Figure 1), the coral cover has dramatically decreased, probably due to a population outbreak of the coraleating starfish Acanthaster planci in 1983, and recurrent coral-bleaching events after 1998

2 Sesoko Station, Tropical Biosphere Research Center, University of the Ryukyus, Sesoko, Motobu, Okinawa 905-0227, Japan.

${ }^{3}$ Institute of Biogeosciences, Japan Agency for Marine-Earth Science and Technology (JAMSTEC), Natsushima, Yokosuka, Kanagawa 237-0061, Japan.

${ }^{4}$ Geological Survey of Japan, National Institute of Advanced Industrial Science and Technology (AIST), Higashi, Tsukuba, Ibaraki 305-8567, Japan.

${ }^{5}$ Faculty of Science, University of the Ryukyus, Nishihara, Okinawa 903-0213, Japan.

${ }^{6}$ Corresponding author (e-mail: naoko_m_@nifty .com). 
(a)
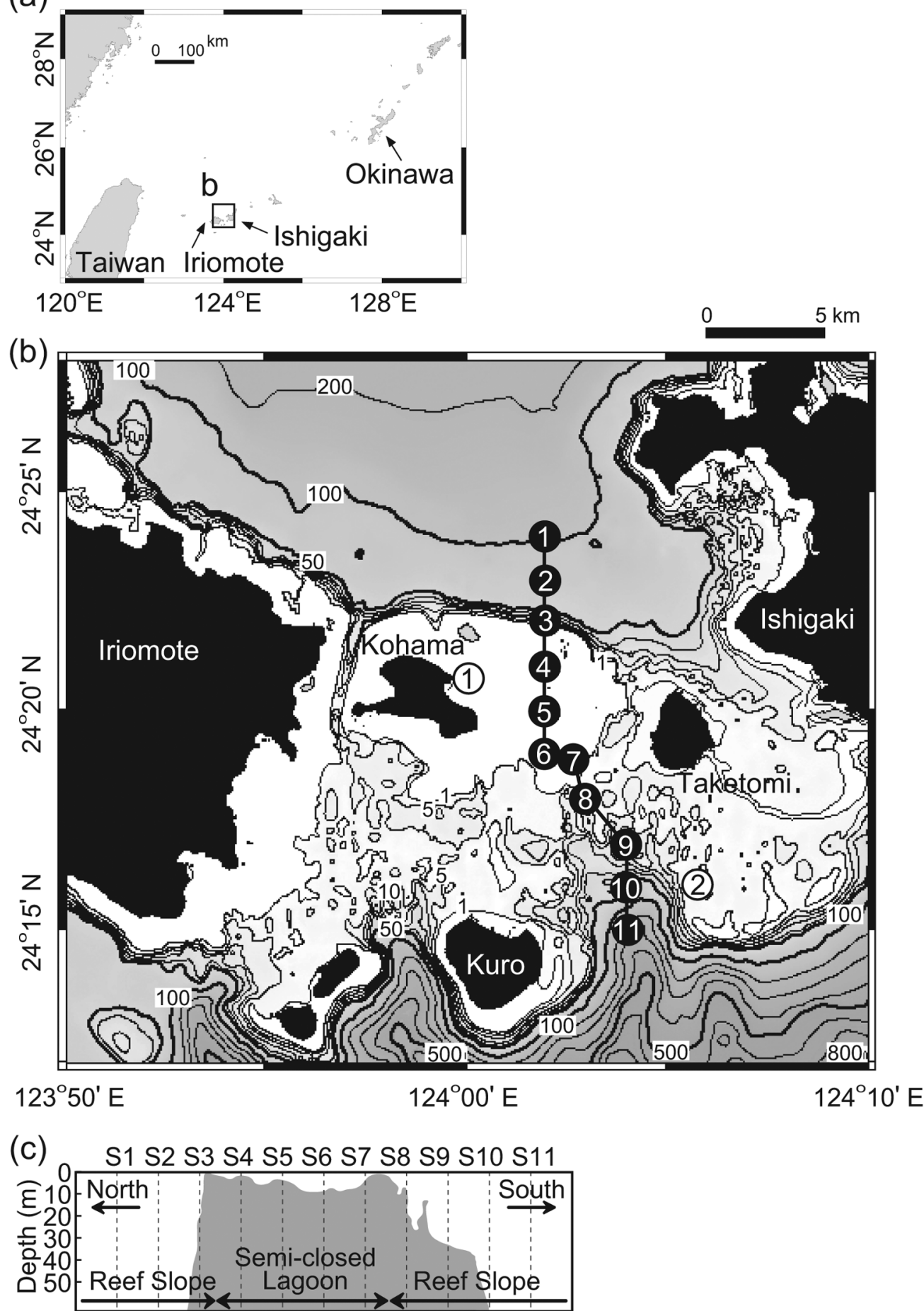

Figure 1. Study site: (a), Ryukyu Archipelago. (b), Observation stations in Sekisei Reef and depth-contour map. Each circled number indicates station number; solid circles correspond to sampling stations $\mathrm{S} 1-\mathrm{S} 11$, and open circles to stations T1 and T2, where the water temperature is continually monitored. (c), Cross-sectional diagram along transect line, which was drawn based on a hydrographic chart (based on Japan Coast Guard 1992). 
have caused additional degradation of coral communities (Yamaguchi 1986, Environment Agency 1999, Sato 2008). In 1983, coral cover exceeded $50 \%$ inside the semiclosed lagoon and at reef slopes outside the lagoon, but after the mid-1980s coral cover never exceeded $50 \%$ inside the lagoon, according to subsequent surveys (Mori 1995, Environment Agency 1999-2001, Ministry of the Environment 2002, 2003). In contrast, coral cover exceeded $70 \%$ at some stations outside the lagoon in those surveys. Bellwood et al. (2004) suggested that a dramatic shift from coral to algal dominance in reef communities (phase shift) may occur after intense disturbance of coral communities, if eutrophication progresses. Actually, Umezawa et al. (2002) reported that $\mathrm{NO}_{3}-\mathrm{N}$ concentrations of groundwater discharged to coral reefs were higher at Shiraho Reef, which is located about $10 \mathrm{~km}$ east of Sekisei Reef, than at other reefs in Ishigaki Island, probably due to intensive land use of the watershed. Although some reports showed high silt accumulation on the seabed inside the lagoon (Environment Agency 1999-2001, Ministry of the Environment 2002, 2003), there had been no systematic study of water-quality parameters at Sekisei Reef. Therefore, water-quality investigations were conducted at Sekisei Reef to determine whether the poor recovery of coral communities inside the lagoon is related to water-quality degradation.

In high-latitude coral reefs, temporal variation in eutrophication indicators (i.e., nutrients and chlorophyll concentrations) differs greatly among reefs, resulting in difficulties in evaluating these parameters. Generally speaking, nutrients and chlorophyll concentrations of coral reefs are higher than those of offshore areas (e.g., Hatcher and Hatcher 1981, Furnas et al. 1990). This pattern is considered to be caused mainly by nutrient release to the water column through regeneration processes by microorganisms inhabiting interstices of bottom sediments and reef frameworks $(\mathrm{Ca}-$ pone et al. 1992, Richter et al. 2001, Scheffers et al. 2004). However, seasons in which nutrients and chlorophyll concentrations peak differ among reefs (e.g., Hatcher and Hatcher 1981, Rasheed et al. 2002), and Ayukai (1993) reported that dissolved inorganic nitrogen (DIN) concentration increased with increasing wind velocity. In addition, nutrients are assimilated by primary producers (Conway 1977, D'Elia and DeBoer 1978). Thus, the release rate by regeneration and biological activity appear to vary temporally in subtropical climates. Terrestrial discharge by heavy rainfall and upwelling also confound the temporal variation (Szmant and Forrester 1996, Lapointe et al. 2004).

In this study, to reveal the differences in water quality inside and outside the lagoon at Sekisei Reef and to elucidate the temporal variations in nutrients and chlorophyll concentrations in a high-latitude coral reef, seawater sampling was conducted along a transect line crossing the lagoon. Turbidity, chlorophyll- $a, \mathrm{NO}_{x}-\mathrm{N}\left(\mathrm{NO}_{3}-\mathrm{N}+\mathrm{NO}_{2}-\mathrm{N}\right)$, and $\mathrm{NH}_{4}-\mathrm{N}$ concentrations as eutrophication indicators, and temperature and salinity as basic physical indicators, were quantified. We analyzed the spatial and temporal variations of these parameters, and the effects of wind velocity and precipitation on the former four parameters were statistically tested.

\section{MATERIALS AND METHODS}

\section{Study Area}

Sekisei Reef $\left(24^{\circ} \mathrm{N}, 124^{\circ} \mathrm{E}\right)$ is located in the Ryukyu Archipelago, in the southernmost region of Japan (Figure 1a). This reef is composed of barrier reefs with a shallow lagoon (usually $<10 \mathrm{~m}$ in depth) and fringing reefs surrounding islands (Figure $1 b$ ). The climate is subtropical, and the mean monthly air temperature is highest in July $\left(29.3^{\circ} \mathrm{C}\right)$ and lowest in January $\left(18.3^{\circ} \mathrm{C}\right)$, according to observations conducted at Ishigaki Island from 1971 to 2000 (Japan Meteorological Agency 2008). The mean annual precipitation is $2,061 \mathrm{~mm}$. There is a rainy season from May to June, and several typhoons hit or approach the site from July to October. Among islands in and around Sekisei Reef, the human population density is highest in Ishigaki Island (213 $\left.\mathrm{km}^{-2}\right)$ followed by Kohama Island $\left(81 \mathrm{~km}^{-2}\right.$ [Okinawa Prefecture 2008]). No upwelling has been observed around Sekisei Reef. 


\section{Sampling Strategy}

We repeatedly conducted water samplings at 11 stations (S1-S11) on a north-south transect line across the lagoon (Figure $1 b$ ). Stations S4-S7 were located inside the semiclosed lagoon, and the other stations were on the northern $(\mathrm{S} 1-\mathrm{S} 3)$ or southern $(\mathrm{S} 8-\mathrm{S} 11)$ reef slopes. We carried out shipboard investigations five times in summer (October 2004; June, August, September, and November 2005 ) and three times in winter (January and March 2005, March 2006) by sampling the surface seawater using a 10-liter bucket and by casting a conductivity-temperature-depth (CTD) profiler tied with a rope approximately $50 \mathrm{~m}$ long at each station within 10 min. Each survey was carried out during the daytime, from the time of low tide to that of an incoming tide, except in March 2006, when it was carried out during the ebb tide; each survey was completed within a few hours.

\section{Quantification of the Water Quality}

The following parameters of the surface seawater were measured at each station: (1) temperature, (2) salinity, (3) turbidity, (4) chlorophyll- $a$ concentration, (5) $\mathrm{NO}_{x}-\mathrm{N}$ concentration, and (6) $\mathrm{NH}_{4}-\mathrm{N}$ concentration. We could not conduct sampling at S1-S3 and S8 in January 2005 or quantify the turbidity at any of the stations in November 2005. In addition, vertical distributions of temperature, salinity, and chlorophyll- $a$ concentration were also measured at $0.1 \mathrm{~m}$ intervals from the surface to the seabed (or up to a depth of $48 \mathrm{~m}$ at stations with a greater water depth) by using CTD profilers, and the values were averaged every $1 \mathrm{~m}$. We used two types of CTD profilers: (1) a Compact-CTD (ALEC Electronics Co. Ltd., Kobe, Japan) with an accuracy of $0.01^{\circ} \mathrm{C}$ (temperature) and 0.01 (salinity) for the temperature and salinity measurements conducted in October 2004 and January, March, and August 2005; and (2) an ACL208DK (ALEC Electronics Co. Ltd., Kobe, Japan) with an accuracy of $0.01^{\circ} \mathrm{C}$ (temperature), 0.01 (salinity), and $0.01 \mu \mathrm{g}$ liter $^{-1}$ (chlorophyll concentration) for those conducted from June 2005 to March 2006. Both profilers were calibrated by comparing their measurements with those of manual analyses and by regular assessments. Because chlorophyll data obtained by an ACL208DK were originally calibrated by uranine fluorescence, those were calibrated by chlorophyll- $a$ concentrations obtained by manual analyses, and those values showed high correlation. With regard to the water-quality values of surface seawater, the temperature was further measured with an accuracy of $0.1^{\circ} \mathrm{C}$ using a digital thermometer (SK-250WP [Sato Keiryoki Mfg. Co. Ltd., Tokyo, Japan]). The surface chlorophyll- $a$ concentration was calculated as the mean of the calibrated CTD vertical data determined for a depth of $0.5-1.4 \mathrm{~m}$ from June 2005 to March 2006.

Surface seawater samples collected at each station were stored in $500 \mathrm{ml}$ polyethylene bottles and taken to the laboratory for analysis of salinity and turbidity. For analysis of $\mathrm{NO}_{x}-\mathrm{N}$ and $\mathrm{NH}_{4}-\mathrm{N}$ concentrations, water samples were immediately filtered through Sartorius polycarbonate in-line filters (pore size, $0.45 \mu \mathrm{m}$ ) by using an acid-rinsed syringe and frozen and preserved in $10 \mathrm{ml}$ acid-rinsed acrylic tubes. Salinity of the samples was quantified with an inductively coupled salinometer (601Mk1V [Yeo-Kal Electronics Pty. Ltd., Brookvale, Australia], accuracy 0.001). Turbidity was measured with a turbidimeter (2100P Portable Turbidimeter [HACH Co., Loveland, Colorado], accuracy 0.01 nephelometric turbidity units [NTU]) after being calibrated with stabilized formazin standards. $\mathrm{NO}_{x}-\mathrm{N}$ and $\mathrm{NH}_{4}-\mathrm{N}$ concentrations of the water samples were determined using an automated segmented flow analyzer (AACS3 [Bran-Luebbe, Norderstedt, Germany]), according to the method described by Strickland and Parsons (1972). The analytical detection limits (ICH 1996) were 0.05 NTU for turbidity, $0.03 \mu \mathrm{M}$ for $\mathrm{NO}_{x}-\mathrm{N}$ concentration, and $0.04 \mu \mathrm{M}$ for $\mathrm{NH}_{4}-\mathrm{N}$ concentration. Each datum below the detection limit was replaced with $50 \%$ of the value of the limit.

In addition, two thermal loggers were used: (1) an Aquadopp Profiler (Nortek AS, Rud, Norway) that was placed within the lagoon (T1; depth, $6.6 \mathrm{~m}$ ) and was used to obtain measurements at $20 \mathrm{~min}$ intervals from $\mathrm{Au}-$ gust 2004 to December 2005, and (2) an 
MDS-MkV/T (ALEC Electronics Co. Ltd., Kobe, Japan) that was placed outside the lagoon (T2; depth, $6 \mathrm{~m}$ ) and was used to obtain measurements at $10 \mathrm{~min}$ intervals from $\mathrm{Au}-$ gust 2004 to March 2006.

\section{Statistical Analyses}

A principal component analysis (PCA) was conducted independently for each of the six parameters of surface-seawater quality. The data subjected to each analysis were arranged within a spatiotemporal matrix, with stations and sampling months as rows and columns, respectively. Before the statistical analysis, a column in which some values were missing (i.e., the column corresponding to January 2005) was removed from the matrix because a PCA data matrix should have no missing values.

To examine the effects of wind velocity on each of the four water-quality parameters (i.e., turbidity, chlorophyll- $a, \mathrm{NO}_{x}-\mathrm{N}$, and $\mathrm{NH}_{4}-\mathrm{N}$ concentrations), we first analyzed the four water-quality variables using multivariate analysis of covariance (MANCOVA) with Wind (covariate), Area (that inside and outside the lagoon), the interaction between Wind and Area, and Station (S1 to S11; nested within Area) as independent variables and then conducted univariate analysis of covariance (ANCOVA) on each dependent variable. In addition, the effects of cumulative precipitation over a period of 1 day were analyzed in a similar manner. The wind velocity and precipitation scores used in the analyses were the hourly means during samplings and the hourly summation for $24 \mathrm{hr}$ (1 day) before samplings, respectively, recorded at Ishigaki Island (Japan Meteorological Agency 2008), and for each sampling date the same values were used across all the stations.

\section{RESULTS}

\section{Meteorological Conditions and Seawater Temperature}

The air and seawater temperatures exhibited similar seasonal variations, but the former fluctuated dramatically during winter (Figure 2 , a). Seasonal means of the cumulative precipitation averaged in summer and in winter were $13 \mathrm{~mm}$ and $1 \mathrm{~mm}$ over a period of 1 day, respectively, and $143 \mathrm{~mm}$ and $122 \mathrm{~mm}$ over a period of 30 days, respectively. The mean hourly wind velocity during the sampling period was highest in January 2005, and the seasonal means of the mean hourly wind velocity averaged in summer and in winter were $5.4 \mathrm{~m} \mathrm{sec}^{-1}$ and $5.7 \mathrm{~m} \mathrm{sec}^{-1}$, respectively (Figure 2, b). Seasonal variations in the seawater temperatures were slightly greater inside the lagoon (T1) than outside it (T2). The cumulative precipitation recorded before each sampling was highest in June 2005 both over a period of 1 day and over 30 days (Figure 2, c).

\section{PCA of Surface Seawater Parameters}

Focusing on the first and second PCA axes, we found that stations located in the semiclosed lagoon yielded similar PC scores for temperature, salinity, turbidity, and chlorophyll- $a$ concentration (Figure 3, a-d). Scores recorded for stations located outside the lagoon were distinct from those recorded for the stations located within the lagoon. In addition, the PC scores for chlorophyll- $a$ concentration recorded outside the lagoon exhibited different patterns between the northern and southern stations (Figure 3, c). In contrast, the scores recorded for the $\mathrm{NO}_{x}-\mathrm{N}$ and $\mathrm{NH}_{4}-\mathrm{N}$ concentrations did not properly reflect the spatial relationship among the stations (Figure 3, e, f). For all the parameters, the proportions of variance for PC1 were between $61 \%$ and $76 \%$, and those for PC2 were between $14 \%$ and $30 \%$.

\section{Surface-Seawater Parameters in Summer and Winter}

The surface-seawater parameters at each station were averaged in summer and in winter. Temperature was slightly higher in summer and lower in winter inside the lagoon than outside it (Figure 4, a). Salinity was higher in winter than in summer at all stations (Figure $4, b)$. The difference of salinity between inside and outside the lagoon was indistinct in summer, but salinity inside the lagoon was generally higher than that outside it in winter. Turbidity was generally higher inside 


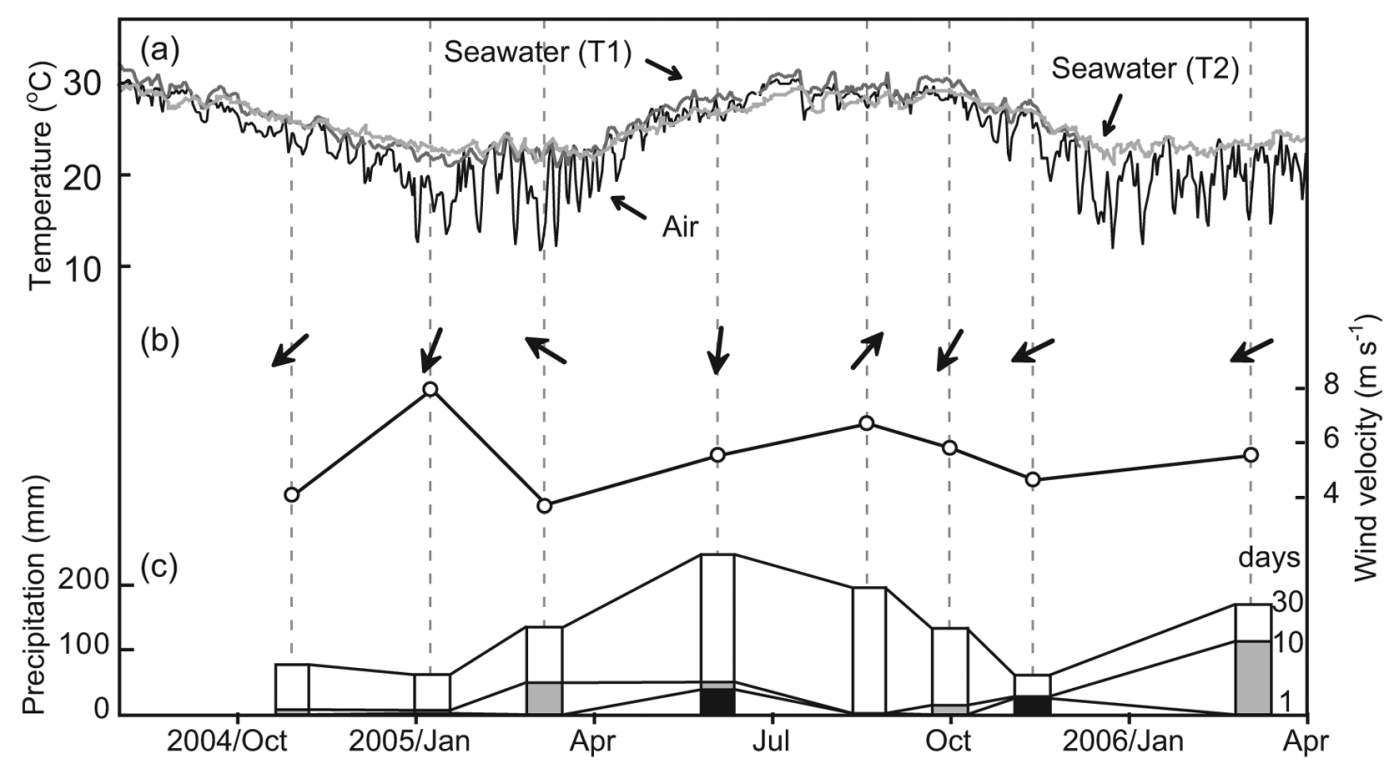

FIgURE 2. (a), Daily mean air temperature at Ishigaki Island and seawater temperature at T1 and T2. Sampling dates are represented as gray dashed lines. (b), Hourly mean wind velocity and wind direction during the sampling at Ishigaki Island (downward arrow indicates north wind). (c), Cumulative precipitation at Ishigaki Island for 1 (black bar), 10 (gray bar along with the black bar), and 30 (bars showing all colors) days before the sampling at each observation date. All climate data at Ishigaki Island were obtained from Japan Meteorological Agency (2008).

the lagoon than outside it in both summer and winter (Figure 4, c). The difference in chlorophyll- $a$ concentration between summer and winter was greater inside the lagoon than outside it (Figure 4, d). The chlorophyll- $a$ concentration inside the lagoon was higher in summer than in winter and was generally higher in summer and lower in winter than that outside the lagoon. The $\mathrm{NO}_{x}-\mathrm{N}$ concentration was higher inside the lagoon than outside it except for stations $\mathrm{S} 3$ and $\mathrm{S} 8$, as shown in the result of PCA (Figure 4, e). The $\mathrm{NH}_{4}$ $\mathrm{N}$ concentration inside the lagoon was lower than that at the neighboring stations outside it in summer, and was higher than that outside it in winter (Figure 4, f). The $\mathrm{NH}_{4}-\mathrm{N}$ concentration inside the lagoon was higher in winter than in summer.

\section{Vertical Distribution of Water Qualities along the Transect Line}

The variations in vertical distributions of temperature and salinity outside the lagoon were larger in summer than in winter, with slight spatial variations in salinity observed in June and November 2005 (data not shown). This indicates that the vertical mixing of the water was stronger in winter than in summer. In contrast, the vertical distributions of these parameters were almost uniform inside the lagoon during all the sampling months.

\section{Effects of Wind and Precipitation on Surface- Seawater Parameters}

In the analyses on the effect of wind velocity, MANCOVA found significant effects of all the independent variables except for stations. The ANCOVA for each water-quality variable indicated that wind velocity had a significant effect on turbidity and $\mathrm{NO}_{x}-\mathrm{N}$ concentration but had no significant effect on other water-quality parameters. Turbidity, chlorophyll- $a$, and $\mathrm{NO}_{x}-\mathrm{N}$ concentrations differed significantly among the areas, but wind velocity-by-area interactions were nonsignificant for all parameters.

In the analyses of the effect of cumulative precipitation over a period of 1 day, the 

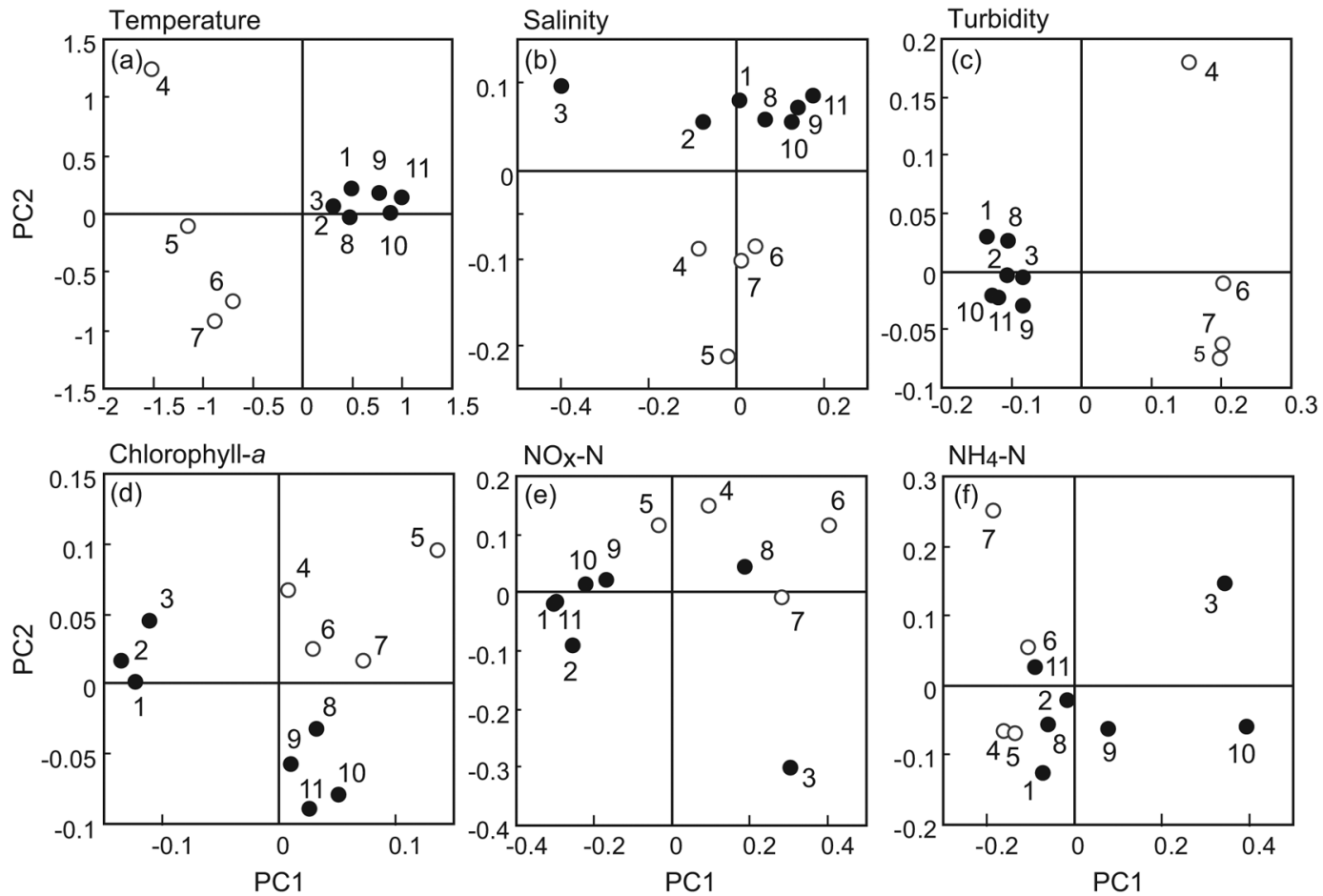

FIgURE 3. PC1 and PC2 scores derived from PCA of $(a)$ temperature, $(b)$ salinity, $(c)$ turbidity, $(d)$ chlorophyll- $a$ concentration, $(e) \mathrm{NO}_{x}-\mathrm{N}$ concentration, and $(f) \mathrm{NH}_{4}-\mathrm{N}$ concentration. Each number represents the station number; white circles indicate stations located inside the lagoon and black ones, outside the lagoon.

MANCOVA found significant effects of all the independent variables except for stations. ANCOVA for each water-quality variable indicated an interaction between precipitation and the areas, and precipitation had a significant effect on $\mathrm{NH}_{4}-\mathrm{N}$ concentration but had no significant effect on the other waterquality parameters. Further, the relationship between $\mathrm{NH}_{4}-\mathrm{N}$ concentration and cumulative precipitation over a period of 1 day indicated that $\mathrm{NH}_{4}-\mathrm{N}$ concentration increased with increasing precipitation outside the lagoon, but not inside it (data not shown).

\section{DISCUSSION}

Both closed topography and shallow depth of the lagoon are likely to affect the observed variation in water-quality parameters at Sekisei Reef. Temperature inside the lagoon was higher in summer and lower in winter than that outside it, and the difference was greater in summer than in winter (Figure 4, a). This is mainly attributable to the climate characteristics typical of the subtropics (i.e., the strong irradiance in summer and the large difference between air and seawater temperatures in winter at Sekisei Reef), and the long retention time of seawater and shallow depth would have enhanced those effects inside the lagoon. On the other hand, salinity was higher in winter than in summer at all stations (Figure 4, b), which appears to reflect the seasonal change of the East China Sea surrounding Sekisei Reef (Chen et al. 2006). However, among the sampling stations, salinity inside the lagoon was higher than that outside it in winter, when the cumulative precipitation over a period of 1 day was smaller than that in summer. This is attributed to evaporation during the long retention time of seawater inside the lagoon.

The observed variation in turbidity and $\mathrm{NO}_{x}-\mathrm{N}$ concentrations was mainly controlled 

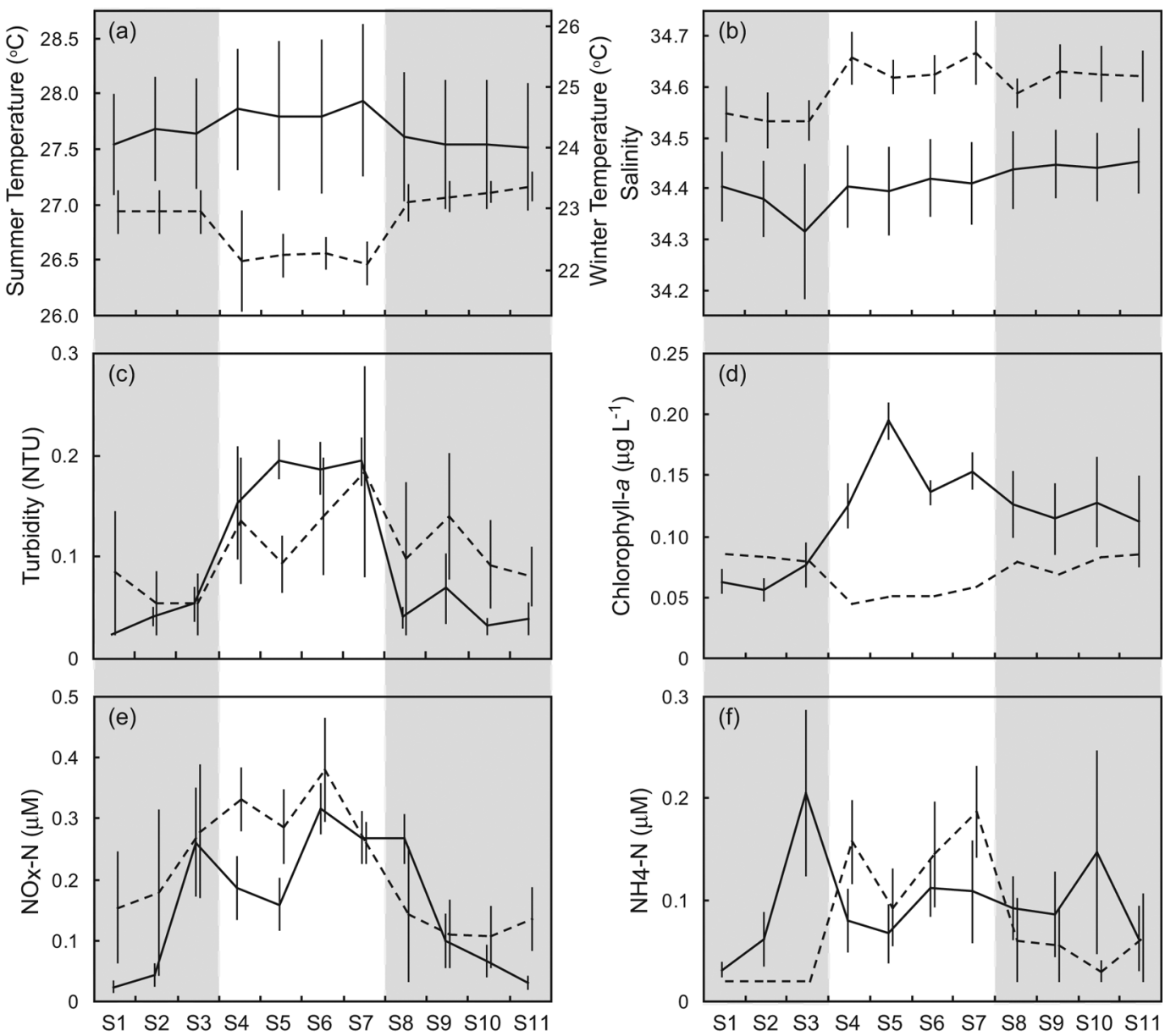

FIgURE 4. Surface seawater $(a)$ temperature, $(b)$ salinity, $(c)$ turbidity, $(d)$ chlorophyll- $a$ concentration, $(e) \mathrm{NO}_{x}-\mathrm{N}$ concentration, and $(f) \mathrm{NH}_{4}-\mathrm{N}$ concentration. Mean values $( \pm \mathrm{SE})$ were calculated for summer and winter seasons at each station. Solid lines represent summer, and dashed lines, winter. Data on gray background were collected outside the lagoon.

by wind. These concentrations increased with increasing wind velocity both inside and outside the lagoon but did not show correlations with precipitation. In addition, these concentrations were significantly higher inside the lagoon than outside it. The significant positive correlation between turbidity and wind velocity suggests that resuspension of bottom sediments by wind-induced strong waves mainly raised the turbidity, as reported in other coral reefs (Larcombe et al. 1995, Ogston et al. 2004). In addition, it was reported that silt had greatly accumulated on the sea- bed of the lagoon at Sekisei Reef (Environment Agency 1999-2001, Ministry of the Environment 2002, 2003). This appears to have contributed to the larger difference in turbidity between inside and outside the lagoon. The observed positive correlation between $\mathrm{NO}_{x}-\mathrm{N}$ concentration and wind velocity suggests that strengthened mixing of seawater by the increase in wind velocity was also attributable to the increase in $\mathrm{NO}_{x}-\mathrm{N}$ concentration. DIN was considered to be produced by the regeneration process by microorganisms inhabiting interstices of bottom 
sediments and reef frameworks in coral reefs (Capone et al. 1992, Richter et al. 2001, Scheffers et al. 2004). The strong mixing of seawater appears to enhance the DIN release from the sediments and reef frameworks, resulting in increased $\mathrm{NO}_{x}-\mathrm{N}$ concentration. Similarly, in coral reefs of the Gulf of Aqaba $\left(29^{\circ} \mathrm{N}\right)$, Rasheed et al. (2002) reported that the DIN concentration was higher in winter than in summer and pointed out an intensified three-dimensional mixing of seawater in winter as one of the reasons for the observed pattern. The closed topography and shallow depth inside the lagoon are likely responsible for the strong effects of wind on turbidity and $\mathrm{NO}_{x}-\mathrm{N}$ concentration.

Outside the lagoon, the variations in $\mathrm{NH}_{4}-$ $\mathrm{N}$ concentration appear to be influenced by precipitation. The $\mathrm{NH}_{4}-\mathrm{N}$ concentration increased with increasing precipitation outside the lagoon, which suggests that successive terrestrial discharge due to rainfall appears to have raised the $\mathrm{NH}_{4}-\mathrm{N}$ concentration outside the lagoon. On the other hand, the $\mathrm{NH}_{4}-\mathrm{N}$ concentration did not increase with increasing precipitation inside the lagoon. This suggests that another factor may have mainly controlled the $\mathrm{NH}_{4}-\mathrm{N}$ concentration inside the lagoon.

Increased temperature and irradiance in summer, and the long retention time of seawater may have caused the observed variation in $\mathrm{NH}_{4}-\mathrm{N}$ concentration inside the lagoon of Sekisei Reef. $\mathrm{NH}_{4}-\mathrm{N}$ concentration was lower in summer than in winter inside the lagoon and was lower inside the lagoon than at the neighboring stations outside it in summer (Figure 4, f). In general, $\mathrm{NH}_{4}-\mathrm{N}$ is preferentially assimilated by primary producers like phytoplankton and macroalgae (Conway 1977, D'Elia and DeBoer 1978). During summer, primary producers likely increased rapidly due to high temperatures and strong irradiance by consuming $\mathrm{NH}_{4}-\mathrm{N}$ inside the lagoon, where they could stay for a long time due to the long retention time of the seawater. In contrast, in winter they could not have increased greatly probably because of low temperature and weak irradiance. In fact, chlorophyll- $a$ concentration was higher inside the lagoon than outside it in summer and was lower inside the lagoon than outside it in winter (Figure 4, d).

Observed higher turbidity and nutrients concentrations, and larger variations in temperature might have more negatively affected the recovery of coral communities inside the lagoon than those outside it at Sekisei Reef. Turbidity and $\mathrm{NO}_{x}-\mathrm{N}$ concentration through the year, and chlorophyll- $a$ concentration in summer were higher inside the lagoon than outside it. These concentrations were not as high as those reported in coral reefs where serious anthropogenic effects were reported (Fabricius 2005, Costa et al. 2006). However, Bell et al. (2007) pointed out that the nutrient threshold concentrations causing a dramatic shift from coral to algal dominance in reef communities would be low if sensitive coral species were dominant and, in particular, the area was in a low flushing regime. Thus, benthic algae, whose growth was facilitated by slightly but continuously high $\mathrm{NO}_{x}-\mathrm{N}$ concentration and released $\mathrm{NH}_{4}-\mathrm{N}$ through the regeneration process by benthic microorganisms, might have inhibited coral settlement inside the lagoon. A higher volume of bottom sediments might have further inhibited coral settlement, and higher $\mathrm{NO}_{x}-\mathrm{N}$ concentration and turbidity might have prevented coral growth and reproduction inside the lagoon, as suggested by experimental studies (e.g., Gilmour 1999, Ferrier-Pages et al. 2000, Harrison and Ward 2001). In addition, temperature, which showed higher variation inside the lagoon than outside it, may carry a risk of inducing coral bleaching both in summer and winter. Therefore, the multiple effects by these water-quality variables might have caused the poor recovery of coral communities inside the lagoon at Sekisei Reef. Recent expansion of land use on the nearby islands might have contributed to the waterquality degradation inside the lagoon through greater terrestrial discharge than before. If this is the case, natural recovery of coral communities inside the lagoon appears to be difficult. Future studies should investigate the dynamics of coral populations and communities in relation to water quality such as reduction of the growth rate and inhibition of coral settlement by blooming algae, in addi- 
tion to other eutrophication parameters like particulate and dissolved organic nutrients, and the fluctuations of water quality just after heavy rainfall.

\section{ACKNOWLEDGMENTS}

We thank T. Yarabu and M. Uehara for their assistance with the water sampling, the International Coral Reef Research and Monitoring Center for the provision of laboratory facilities, and General Environmental Technos Co. Ltd. for improving the analytical techniques used. Many thanks to I. Koike for valuable suggestions on the manuscript.

\section{Literature Cited}

Ayukai, T. 1993. Temporal variability of the nutrient environment on Davies Reef in the central Great Barrier Reef, Australia. Pac. Sci. 47:171-179.

Bell, P. R. F., B. E. Lapointe, and I. Elmetri. 2007. Reevaluation of ENCORE: Support for the eutrophication threshold model for coral reefs. Ambio 36:416-424.

Bellwood, D. R., T. P. Hughes, C. Folke, and M. Nystrom. 2004. Confronting the coral reef crisis. Nature (Lond.) 429:827-833.

Capone, D. G., S. E. Dunham, S. G. Horrigan, and L. E. Duguay. 1992. Microbial nitrogen transformations in unconsolidated coral reef sediments. Mar. Ecol. Prog. Ser. 80:75-88.

Chen, X., X. Wang, and J. Guo. 2006. Seasonal variability of the sea surface salinity in the East China Sea during 1990-2002. J. Geophys. Res. 111:C05008.

Conway, H. L. 1977. Interactions of inorganic nitrogen in the uptake and assimilation by marine phytoplankton. Mar. Biol. (Berl.) 39:221-232.

Costa, O. S., M. J. Attrill, and M. Nimmo. 2006. Seasonal and spatial controls on the delivery of excess nutrients to nearshore and offshore coral reefs of Brazil. J. Mar. Sys. 60:63-74.

D'Elia, C. F., and J. A. DeBoer. 1978. Nutritional studies of two red algae. II. Kinetics of ammonium and nitrate uptake. J. Phycol. 14:266-272.
Environment Agency. 1999, 2000, 2001. Report of coral reef monitoring of the Sekisei Lagoon and its adjacent waters, Yaeyama Islands, Okinawa [in Japanese]. Tokyo.

Fabricius, K. E. 2005. Effects of terrestrial runoff on the ecology of corals and coral reefs: Review and synthesis. Mar. Pollut. Bull. 50:125-146.

Ferrier-Pages, C., J. P. Gattuso, S. Dallot, and J. Jaubert. 2000. Effect of nutrient enrichment on growth and photosynthesis of the zooxanthellate coral Stylophora pistillata. Coral Reefs 19:103-113.

Furnas, M. J., A. W. Mitchell, M. Gilmartin, and N. Revelante. 1990. Phytoplankton biomass and primary production in semienclosed reef lagoons of the central Great Barrier Reef, Australia. Coral Reefs 9:110.

Gilmour, J. 1999. Experimental investigation into the effects of suspended sediment on fertilisation, larval survival and settlement in a scleractinian coral. Mar. Biol. (Berl.) 135:451-462.

Harrison, P. L., and S. Ward. 2001. Elevated levels of nitrogen and phosphorus reduce fertilisation success of gametes from scleractinian reef corals. Mar. Biol. (Berl.) 39:1057-1068.

Hatcher, A. I., and B. G. Hatcher. 1981. Seasonal and spatial variation in dissolved inorganic nitrogen in One Tree Reef lagoon. Proc. 4th Int. Coral Reef Symp. 1:419-424.

ICH (International Conference on Harmonisation of Technical Requirements for Registration of Pharmaceuticals for $\mathrm{Hu}-$ man Use). 1996. Guidance for Industry Q2B, Validation of analytical procedures: Methodology. Rockville, Maryland.

Japan Coast Guard. 1992. Basic maps of the sea in coastal waters in southern part of Ishigaki Shima (submarine structural chart). No. 6513-7-S. Tokyo.

Japan Meteorological Agency. 2008. Annual report on weather observations. http:// www.data.jma.go.jp/obd/stats/etrn/index .php

Knowlton, N., and J. B. C. Jackson. 2008. Shifting baselines, local impacts, and 
global change on coral reefs. PLoS Biol. 6:e54.

Lapointe, B. E., P. J. Barile, and W. R. Matzie. 2004. Anthropogenic nutrient enrichment of seagrass and coral reef communities in the Lower Florida Keys: Discrimination of local versus regional nitrogen sources. J. Exp. Mar. Biol. Ecol. 308:23-58.

Larcombe, P., P. V. Ridd, A. Prytz, and B. Wilson. 1995. Factors controlling suspended sediment on inner-shelf coralreefs, Townsville, Australia. Coral Reefs 14:163-171.

Ministry of the Environment. 2002, 2003. Report of the coral reef monitoring survey of the Sekisei Lagoon and its adjacent waters, Yaeyama Islands, southern Ryukyus [in Japanese]. Tokyo.

Mori, M. 1995. Change of stony coral and crown-of-thorns starfish in the Sekisei Lagoon. Mar. Parks J. 107:10-15 [in Japanese].

Ogston, A. S., C. D. Storlazzi, M. E. Field, and M. K. Presto. 2004. Sediment resuspension and transport patterns on a fringing reef flat, Molokai, Hawaii. Coral Reefs 23:559-569.

Okinawa Prefecture. 2008. Statistical information for isolate islands in Okinawa. http://www3.pref.okinawa.jp/site/view/ contview.jsp? cateid $=39 \& \mathrm{id}=14408 \&$ page $=1$

Rasheed, M., M. I. Badran, C. Richter, and M. Huettel. 2002. Effect of reef framework and bottom sediment on nutrient enrichment in a coral reef of the Gulf of
Aqaba, Red Sea. Mar. Ecol. Prog. Ser. 239:277-285.

Richter, C., M. Wunsch, M. Rasheed, I. Kotter, and M. I. Badran. 2001. Endoscopic exploration of Red Sea coral reefs reveals dense populations of cavity-dwelling sponges. Nature (Lond.) 413:726-730.

Sato, T. 2008. Coral bleaching events occurred during summer of 2007 at Sekisei Lagoon. Newsletter Lagoon by the International Coral Reef Research and Monitoring Center 10:13-14 [in Japanese].

Scheffers, S. R., G. Nieuwland, R. P. M. Bak, and F. C. van Duyl. 2004. Removal of bacteria and nutrient dynamics within the coral reef framework of Curacao (Netherlands Antilles). Coral Reefs 23:413-422.

Strickland, J. D. H., and T. R. Parsons. 1972. A practical handbook of seawater analysis. Fisheries Research Board of Canada, Ottawa.

Szmant, A. M., and A. Forrester. 1996. Water column and sediment nitrogen and phosphorus distribution patterns in the Florida Keys, USA. Coral Reefs 15:21-41.

Umezawa, Y., T. Miyajima, H. Kayanne, and I. Koike. 2002. Significance of groundwater nitrogen discharge into coral reefs at Ishigaki Island, southwest of Japan. Coral Reefs 21:346-356.

Wilkinson, C., ed. 2004. Status of coral reefs of the world: 2004. Australian Institute of Marine Science, Townsville.

Yamaguchi, M. 1986. Acanthaster planci infestations of reefs and coral assemblages in Japan: A retrospective analysis of control efforts. Coral Reefs 5:23-30. 
